\title{
Effects of 30 days of ketogenic diet on body composition, muscle strength, muscle area, metabolism, and performance in semi-professional soccer players
}

\author{
A. Antonio Paoli ${ }^{1,2,3^{*}}$, Laura Mancin ${ }^{1,3}$, Massimiliano Caprio ${ }^{4}$, Elena Monti ${ }^{1}$, Marco V. Narici ${ }^{1}$, Lorenzo Cenci ${ }^{3}$,
} Fabio Piccini ${ }^{5}$, Matteo Pincella ${ }^{6,7}$, Davide Grigoletto ${ }^{1}$ and Giuseppe Marcolin ${ }^{1}$

\begin{abstract}
Background: A ketogenic diet (KD) is a nutritional approach, usually adopted for weight loss, that restricts daily carbohydrates under $30 \mathrm{~g} /$ day. KD showed contradictory results on sport performance, whilst no data are available on team sports. We sought to investigate the influence of a KD on different parameters in semi-professional soccer players.

Methods: Subjects were randomly assigned to a iso-protein (1.8 $\mathrm{g} / \mathrm{Kg}$ body weight/day) ketogenic diet (KD) or western diet (WD) for 30 days. Body weight and body composition, resting energy expenditure (REE), respiratory exchange ratio (RER), cross sectional area (CSA) and isometric muscle strength of quadriceps, counter movement jump (CMJ) and yoyo intermittent recovery test time were measured.
\end{abstract}

Results: There was a significantly higher decrease of body fat $(p=0.0359)$, visceral adipose tissue (VAT) $(p=0.0018)$, waist circumference $(p=0.0185)$ and extra-cellular water $(p=0.0060)$ in KD compared to WD group. Lean soft tissue, quadriceps muscle area, maximal strength and REE showed no changes in both groups. RER decreased significantly in $\mathrm{KD}(p=0.0008)$. Yo-yo intermittent test improved significantly $(p<0.0001)$ in both groups without significant differences between groups. CMJ significantly improved $(p=0.0021)$ only in KD.

Conclusions: This is the first study investigating the effects of a KD on semi-professional soccer players. In our study KD athletes lost fat mass without any detrimental effects on strength, power and muscle mass. When the goal is a rapid weight reduction in such athletes, the use of a KD should be taken into account.

Trial registration: registered retrospectively on Clinical Trial registration number NCT04078971.

Keywords: Ketogenic diet, Soccer, Body composition, Yo-yo intermittent test, Muscle cross sectional area, Metabolism

\footnotetext{
* Correspondence: antonio.paoli@unipd.it

'Department of Biomedical Sciences, University of Padua, Via Marzolo, 3, 35131 Padua, Italy

${ }^{2}$ Research Center for High Performance Sport, UCAM, Catholic University of Murcia, 30107 Murcia, Spain

Full list of author information is available at the end of the article
} 


\section{Introduction}

Soccer is one of the most popular and well-known sport all over the world [1] and lots of factors need to be considered when handling with elite soccer players [2]. Technical skills, game intelligence, proper mindset, athletic characteristics, general fitness condition and body composition represent essentials features in the make-up of a soccer player. Elite players show excellent values of body composition [3] while semi-professionals usually tended to have worst findings. In Italy, Elites amount to more than 2500 while semi-professionals add up to about 377,000 [4]. The excess of body weight and body fat, lower lean soft tissue, fluid and electrolyte imbalance, is related to detrimental effects upon soccer health and soccer-specific actions such as dribbling, ball control, speed and power [5], thus, for semi professional athletes, who usually perform soccer in their leisure time, a good body composition is recommended even though hard to achieve. To get adequate body composition and maintaining an excellent general health, athletes need to consider several aspects ranging from a correct training program to proper sleep and recovering approach; however, one of the most influencing aspect of body composition is diet [6]. Different nutritional approaches have been used according to specific player's characteristics, eating habits and different energy demands during competitive or non-competitive season [7]. The up to date dietary approaches are also focused on enhancing recovery and preventing injuries by providing antioxidants, vitamins, polyunsaturated fatty acids and collagen [8]. During competitive season, a relatively high carbohydrate diet is usually recommended both on training days and matches [9]. During off-season, semiprofessional players often show an increase of body weight and body fat; in such case it is important to avoid detrimental strategies that are usually recommended before the beginning of in-season [10]. These methods, such as extreme caloric restriction, are deleterious both for health and athletic performance outcomes [11]. As opposed to the drastic energy restriction approaches, the ketogenic diet (KD) is a nutritional strategy consisting of high fat, adequate protein and low carbohydrate intake (less than $5 \%$ of total daily energy intake or $30 \mathrm{~g}$ of carbohydrate $(\mathrm{CHO})$ daily)), in which the amount of total available energy is adequate [12]. Hans Krebs referred to the metabolic state of diet-induced ketosis as "physiological ketosis" to distinguish it from the pathological diabetic ketosis [13]. The physiological function of ketosis is to sustain muscle works and central nervous system functions during reduced glucose availability with the high energy metabolic substrate of ketone bodies (KBs), which are small molecules produced by a process called ketogenesis from fats; by this mechanism ketones allowed ancestors to survive and remain efficient even though deprived of glucose [14]. The ketone bodies (acetoacetate, acetone, and $\beta$-hydroxybutyrate) are produced in the liver under low-carbohydrate availability conditions, acting as an alternative energy source for peripheral tissue, such as skeletal muscle, brain and heart [15] . There are conflicting data about the use of $\mathrm{KD}$ in sports, some researches showed negative effects on performance [16-18] whilst others suggest instead a positive effect or, at least, no detrimental effects [19-23]. As a matter of fact, the use of KD in sports may have different aims if we consider endurance or strength/ power athletes [12]. To the best of our knowledge, no data are available about the effects of KD in team sports. Our hypothesis is that 30 days of KD may be able to maintain muscle mass without affecting specific performance $[19,24]$, while reducing body fat in a model of mixed endurance/power sport such as soccer. Given the above, the purpose of our study was to determine the effects of thirty-days of KD on body composition, muscle strength, muscle area, metabolism and performance in semi-professional soccer players.

\section{Material and methods \\ Participants}

Sixteen semi-professional male soccer players (age $25.5 \pm 2.8$ years; height $179.0 \pm 9.2 \mathrm{~cm}$; body mass $77.2 \pm$ 11.88) who competed in a local team (A.S.D. Riviera Del Brenta, Venezia, category one), were recruited to participate in this study (anthropometric baseline characteristics of subjects are shown in Table 1). Exclusion criteria included a body fat percentage over $32 \%$, (determined via dual energy X-ray absorptiometry DXA), cardiovascular, respiratory, gastrointestinal, thyroid or any other metabolic diseases, weight change $\pm 2 \mathrm{Kg}$ over the last month, adherence to special diets, use of nutritional supplements (except a daily multivitamin-mineral) and use of medication to control blood lipids or glucose and goal-keepers. During the study protocol players were asked to keep their normal and constant training schedule ( $8 \mathrm{~h}$ of training/week) during the study period. All the subjects read and signed the informed consent document with the description of the testing procedures

Table 1 Baseline characteristics of athletes

\begin{tabular}{lll}
\hline & KD $\boldsymbol{n}=\mathbf{8}$ & WD $\boldsymbol{n}=\mathbf{8}$ \\
\hline Age (years) & $25.5 \pm 2.5$ & $25.5 \pm 3.1$ \\
Height $(\mathrm{cm})$ & $178.7 \pm 8.6$ & $179.4 \pm 9.8$ \\
Body Mass (Kg) & $78.19 \pm 11.7$ & $76.15 \pm 12.0$ \\
DXA Body Fat (Kg) DXA & $19.475 \pm 4.0$ & $18.88 \pm 6.6$ \\
DXA Body Fat (\%) DXA & $24.78 \pm 3.5$ & $25.03 \pm 4.4$ \\
BMl (Kg/m $\left.{ }^{2}\right)$ & $24.5 \pm 2.1$ & $25.4 \pm 2.6$ \\
Lean Mass (Kg) & $57.4 \pm 4.5$ & $56.6 \pm 5.1$ \\
\hline
\end{tabular}


approved by the ethical committee of the Department of Biomedical Sciences, University of Padova, and conformed to standards for the use of human subjects in research as outlined in the Declaration of Helsinki, Clinical Trial registration number NCT04078971.

\section{Study design and procedures}

The study was as a randomized, parallel arm, controlled, prospective study. Subjects underwent different measurements in three different consecutive days at the beginning of the study and after 30 days. Measurements were taken by the same operators and in the same conditions.

Subject were randomly assigned to a very low carbohydrate ketogenic diet (KD $n=8$ ) group or Western Diet (WD $n=8$ ) group, through an online computer generated sequence (www.graphpad.

com/quickcalcs/randomN1.cfm), matched for percentage of body fat.

The work load of all athletes was over-imposable because the coach and trainers strictly controlled the training schedule and they were instructed to maintain the same level of physical activity throughout the study. (The study protocol is shown in Fig. 1). Before the start of the experiment a meeting was scheduled in order to advise participants about the protocol of study and to give them the first useful and needed advices.

\section{Dietary intervention}

Before the start of the study, athletes were provided nutritional counseling and resources to better adhere to
KD. Resources included food lists containing the food prohibited and permitted in ketogenic diet and electronic-suggested daily meal plans, meal recipes. The food lists encouraged the consumption of beef, veal, poultry, fish, raw and cooked vegetables without restriction, cold cuts such as dried beef, eggs and seasoned cheese (parmesan), Konjac, fruits with the lowest glycemic index (blueberry, raspberry), raw nuts and seeds, ghee butter, plant oils and fats from avocado, coconut and olives ${ }^{31}$. The drinks permitted were tea, coffee, herbal extracts without sugar and a "Keto cocktail" was allowed once per week, made up of gin and soda. The foods and drinks to be avoided were alcohol, bread, pasta, rice, milk, soluble tea and potatoes (a detailed list is provided in Fig. 2). A nutritional protocol as the KD may be hard to be maintained for long periods due to the lack of sweet taste [25], thus, for this reason, in the last years, many ready-to-eat ketogenic products (RKP) have been created [26] in addition to usual low carbohydrate foods [27]. In our protocol we used some RKP as a ketogenic pasta (selected with a ketogenic ratio of fats: protein+carbohydrate equal to 4:1) (Le Gamberi Foods, Forlì, Italy), and other RKP (specialty meals and drinks) that mimics the taste of carbohydrates [27], constituted principally of high-quality protein ( $18 \mathrm{~g}$ of protein per portion), fibers, and electrolytes (mainly magnesium and potassium) [28] (Tisanoreica ${ }^{\circ}$ by Gianluca Mech S.p.A., Asigliano Veneto, Vicenza, Italy). It has been demonstrated that the use of RKP increases the adherence to the ketogenic nutritional protocol $[25,29,30]$. Both diets were designed to be isoproteic $\left(1.8 \mathrm{~g} \mathrm{x} \mathrm{Kg}^{-1} \mathrm{x}\right.$ body

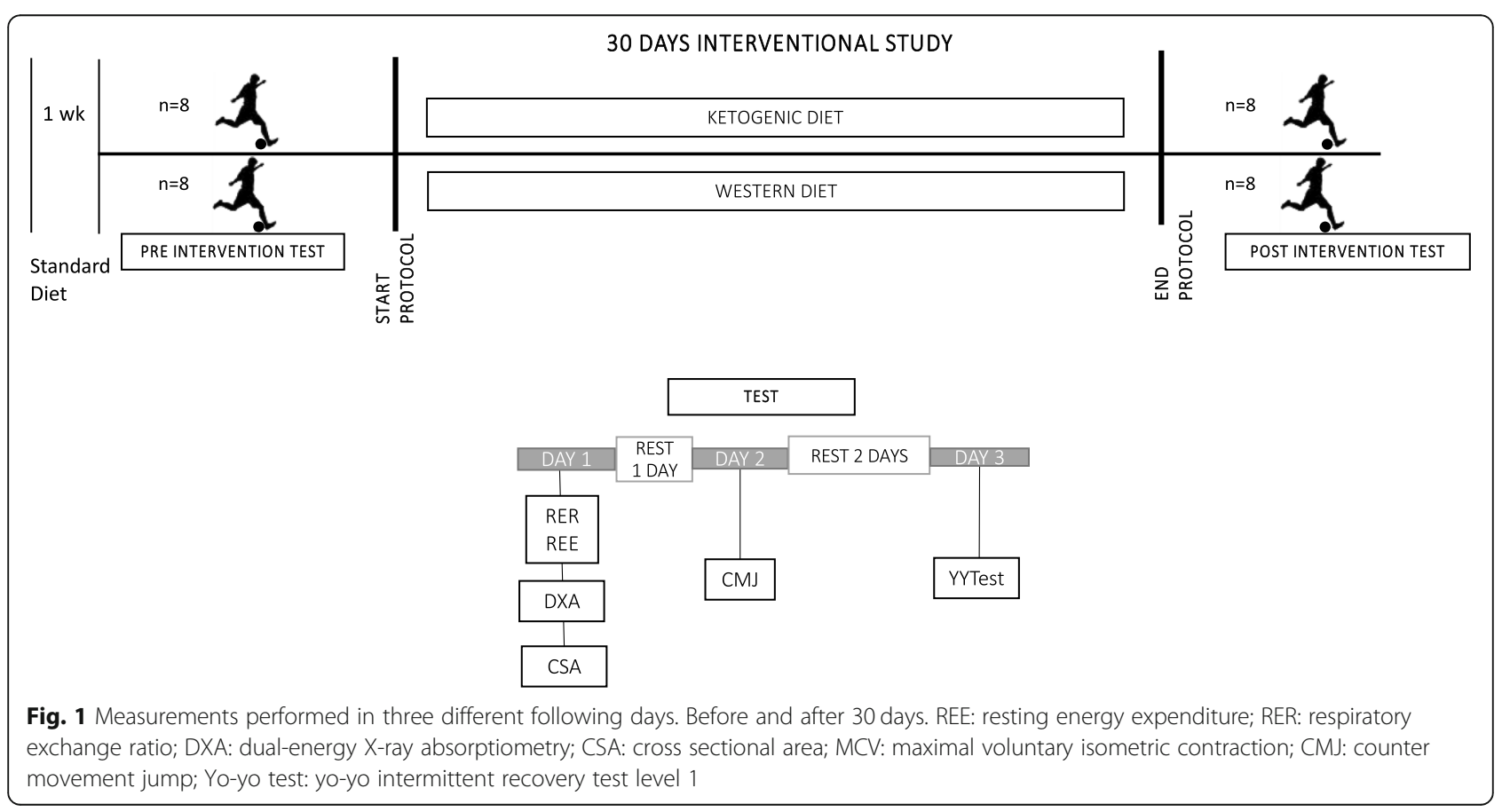



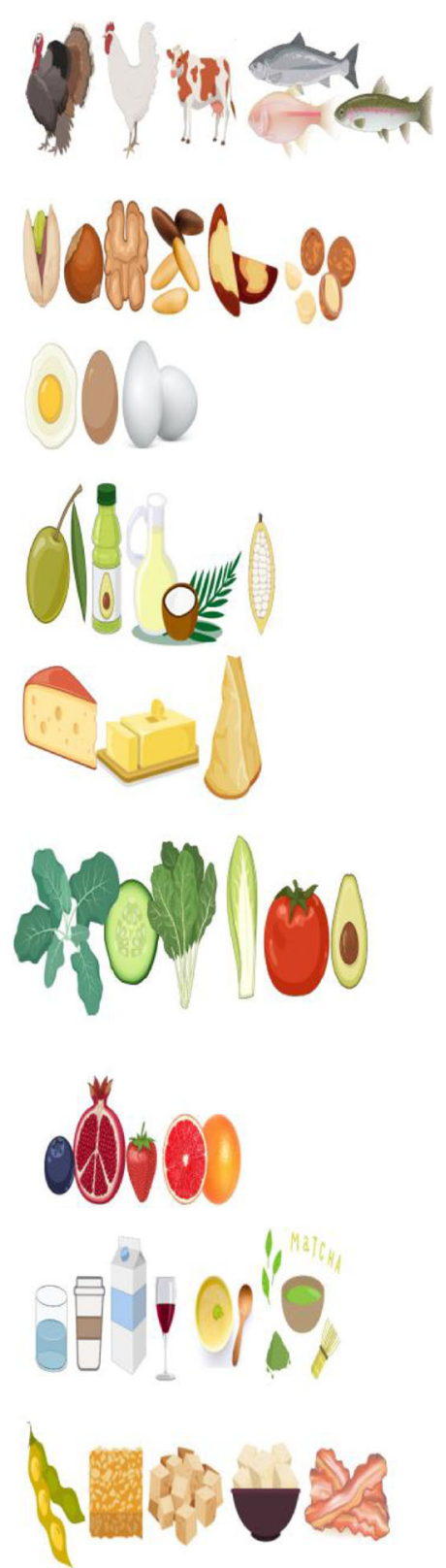

Meat and Fish

Especially unprocessed meats: beef, lamb, pork and poultry

(turkey, duck, chicken). Cod, lobster, fillet, salmon, tuna, sardine, swordfish

Nuts

Macadamia, pecan, almonds, hazelnut, pistachio

Eggs or liquid egg white

Boiled egg, fried in butter, scrambled, omelette

Natural fat, hight-fat sources

Coconut oil, olive oil, cocod

High-fat dairy

Butter, ghee, hight-at cheese (gorgonzola, parmesan), heary cream

Vegetables growing above ground

Fresh or forezen. Especially leafy and green items. Cauliflower,

cabbage, avocado, broccoli, zucchini

Fruits

Berries (blackerry, raspberry, strawberry, bluberry)

Drinks

Water, coffee,green tea, bone broth

Veggie products

Seitan, veggie bacon, tofu, tempeh, soy

Fig. 2 List of food allowed during the ketogenic (created with BioRender.com)

weight ${ }^{-1} \mathrm{x}$ day ${ }^{-1}$ ). The distribution of macronutrients during the very low carbohydrate ketogenic diet (KD) was: carbohydrate $\left(<30 \mathrm{~g} \mathrm{x} \mathrm{day}^{-1}\right.$; $\left.<10 \%\right)$ protein $1.8 \mathrm{~g} \mathrm{x}$ $\mathrm{Kg}^{-1} \mathrm{x}$ body weight ${ }^{-1} \mathrm{x}$ day ${ }^{-1}(\sim 25-30 \%)$, fats $(\sim 65-$ $70 \%)$. Moreover each subject was provided with three herbal extracts (Table 2) according to commercial ketogenic protocol (Tisanoreica ${ }^{\circ}$, Gianluca Mech S.p.A., Asigliano Veneto, Vicenza, Italy). During the first week, subjects were provided with pure medium chain triglyceride oil (MCT oil: $20 \mathrm{~g}$ Named $^{\odot}$ Natural Medicine), in order to facilitate ketosis [31] and to allow players maintaining the same work load during training sessions.
WD group was provided with a diet similar to western diet, thus the intake of protein has been increased to 1.8 $\mathrm{g} \mathrm{x} \mathrm{Kg}^{-1} \mathrm{x}$ body weight ${ }^{-1} \mathrm{x} \mathrm{day}^{-1}$ in order to be isoproteic. The WD was composed mainly of whole cereals (spelt, rye, oat) and pseudo-cereals (buckwheat, quinoa, amaranth), whole grain pasta, potatoes, meet, fish, vegetables, fruit, legumes, olive oil, milk and red wine (at most 1 glass per day). The WD was composed to ensure a constant energy and macronutrient balance: protein $1.8 \mathrm{~g} \mathrm{x} \mathrm{Kg}^{-1} \times$ body weight ${ }^{-1} \mathrm{x} \mathrm{day}^{-1},(\sim 30 \%)$, fats $20-25 \%$ and carbohydrate $\sim 50-55 \%$. WD diet was also designed to contain $<10 \%$ saturated fat and $<300 \mathrm{mg}$ 
Table 2 Plant extracts and composition

\begin{tabular}{|c|c|}
\hline $\begin{array}{l}\text { Plant } \\
\text { extracts }\end{array}$ & Composition \\
\hline $\begin{array}{l}\text { Extracts } 1, \\
\mathrm{ml} / \text { day }\end{array}$ & $\begin{array}{l}\text { Durvillea antarctica, black radish, mint, liquorice, } \\
\text { artichoke, horsetail, burdock, dandelion, rhubarb, } \\
\text { gentian, lemon balm, chinaroot, juniper, spear grass, } \\
\text { elder, fucus, anise, parsley, bearberry, horehound }\end{array}$ \\
\hline $\begin{array}{l}\text { Extracts 2, } \\
\mathrm{ml} / \text { day }\end{array}$ & $\begin{array}{l}\text { Horsetail, asparagus, birch, cypress, couch grass, corn, } \\
\text { dandelion, grape, fennel, elder, rosehip, anise }\end{array}$ \\
\hline $\begin{array}{l}\text { Extracts } 3 \\
\mathrm{ml} / \text { day }\end{array}$ & $\begin{array}{l}\text { Eleuthero, eurycoma longifolia, ginseng, corn, miura } \\
\text { puama, grape, guaranà, arabic coffee, ginger }\end{array}$ \\
\hline $\begin{array}{l}\text { Extracts } 4 \\
\mathrm{ml} / \text { day }\end{array}$ & $\begin{array}{l}\text { L. usitatissimum L., Gelidium amansii, Rheum officinalis L., } \\
\text { Cynara scolymus L., Matricaria chamomilla L., Gentiana } \\
\text { lutea L., Mentha piperita L., Pimpinella anisum L., } \\
\text { Glycyrrhiza glabra L., Raphanus sativus L., Foeniculum } \\
\text { vulgare Mill., A. officinalis L., Melissa officinalis L., } \\
\text { Juniperus communis L. }\end{array}$ \\
\hline
\end{tabular}

cholesterol/day. In both groups, protein intake has been well drafted and divided throughout the day. Protein intake was distributed equally throughout the day (every $3-4 \mathrm{~h})$. Pre-sleep casein protein intake $(30-40 \mathrm{~g})$ was provided in both group after training evening session, as indicated by ISSN [32]. In addition, it has been recommended to athletes to drink an adequate intake fluids during the day $(\sim 1500-2000 \mathrm{~mL})$, especially before and after training sessions and match $(300-500 \mathrm{~mL}$ before and $500 \mathrm{~mL}$ after training). The diets were explained to all subjects during an individual visit and dietary intake was measured by validated 3-food-diary that has been used in the past in studies with athletes [33] and analyzed by Nutritionist Pro ${ }^{\mathrm{Tm}}$ (AxxyA systems, Arlington, $V A)$. Subjects received thorough instruction for completing detailed weighed food records during 7 day-periods for each diet. Food measuring utensils and scales were provided to subjects to ensure an accurate reporting of foods and beverages amounts consumed. To ensure that carbohydrates were restricted throughout the KD diet, subjects tested their urine daily using reagent strips at the same time of the day (Ketostix semiquantitative urine strips, Bayer, Leverkusen, Germany), recording the result on $\log$ sheet and, once or twice a week subjects were tested by GlucoMen LX Plus (Menarini Diagnostics, Firenze, Italy) to detect ketones concentration in capillary blood. Subjects received follow-up counselling and dietetic education if necessary. A whatsApp (Facebook Inc., Mountain View, CA, USA) group was created and some applications for smartphone were provided (Ketodiet tracker, https://ke.to; Keto-app, https://ketodietapp. com), in order to track their food daily intake. Moreover, the nutritionist contacted each participant weekly to ensure a proper dietary adherence. While the WD group received nutritional guidelines on how to formulate a WD diet according to their daily energy requirements, the KD group's suggestion included information on how to formulate a KD diet and a more accurate "shopping list and example meal plans". Both KD and WD subjects were followed by an app to verify the adherence to diet.

\section{Body composition}

Body weight was measured to the nearest $0.1 \mathrm{Kg}$ using an electronic scale (Tanita BC-545 N Amsterdam, Netherlands), and height to the nearest $1 \mathrm{~cm}$ using a wall-mounted stadiometer (GIMA S.p.a., Milan, Italy). Whole body and regional body composition were measured in the morning after a $12 \mathrm{~h}$ overnight fast by dual energy X-ray absorptiometry (DEXA, Hologic Horizon TM QDR RSeries Bedford, Massachusetts, USA) (fat mass: $\mathrm{ICC}=0.995, \mathrm{SEM}=0.81 \mathrm{Kg}$; lean soft tissue: $\mathrm{ICC}=$ $0.995, \mathrm{SEM}=0.83 \mathrm{Kg}$ ). Regional analysis of body composition, trunk and visceral adipose tissue (VAT) were calculated according to anatomical landmarks by the same technician using computer algorithms (software APEX 3.0, Hologic Bedford, Massachusetts, USA) (ICC = 0.99 , SEM $=7.7 \mathrm{~g}$ ). All scans were performed by a qualified physician. Calibration of the densitometer was checked daily against standard calibration block supplied by the company (Phantom 21, 965 Lumbar spine with characteristics of 4 hydroxyapatite vertebrae included in resin. Coefficent of Variation: $0.415 \%)$. Extra cellular water has been measured by bioelectrical impedance analysis (BIA 101 AKERN R New Edition BodyGram Plus, Pontassieve, Florence, Italy) and waist circumference was measured by an anthropometric tape to the nearest $0.001 \mathrm{~m}$. All measurements were taken by the same operator before and after the study according to standard procedures [34].

\section{Ventilatory parameters}

Resting energy expenditure (REE) and respiratory exchange ratio (RER) measurements were made by indirect calorimetry after an overnight fast $(>12 \mathrm{~h}$ ) with subjects resting supine in comfortable thermoneutral conditions, approximately $23^{\circ} \mathrm{C}$.

The gas analysis system was used (Vmax Encore 29 System Vmax, Viasys Healthcare, Inc., Yorba Linda, CA, USA): oxygen uptake and carbon dioxide output values were measured and used to calculate REE and RER using the modified Weir equation [35] The metabolic cart was calibrated with standard gas mixture each morning. Subject were instructed to relax quietly in a dimly lit room without sleeping for $30 \mathrm{~min}$ and oxygen consumption $\left(\mathrm{VO}_{2}\right)$ and dioxide production $\left(\mathrm{VCO}_{2}\right)$ were averaged during the last $20 \mathrm{~min}$ for determination of respiratory exchange ratio (RER) [36], oxygen uptake was measured $\left(\mathrm{mL} \times \mathrm{min}^{-1}\right)$ and also normalized to body weight $\left(\mathrm{mL}^{-1} \times \mathrm{Kg}^{-1} \times \mathrm{min}^{-1}\right)$. REE: $\mathrm{ICC}=0.99, \mathrm{SEM}=0.2$ $\mathrm{mL}^{-1} \times \mathrm{Kg}^{-1} \times \mathrm{min}^{-1}$. RER: $\mathrm{ICC}=0.97, \mathrm{SEM}=0.02$. 


\section{Ultrasound and isometric muscle strength test}

Muscle CSA of the quadriceps was measured in vivo using extended-field-of-view (EFOV) ultrasonography imaging (Mylab70, Esaote, Genoa, Italy). A $50 \mathrm{~mm}, 7.5$ $\mathrm{MHz}$ linear array probe was used to obtain images. The $50 \%$ of the vastus lateralis length (measured from greater trochanter to the superior border of the patella) was calculated and marked with a skin-marker. The operator then positioned the probe on the medial portion of the leg, thus starting the acquisition when the medial borders of the vastus medialis had been identified. The acquisition was stopped after visualizing the lateral borders of the vastus lateralis. The pressure was kept constant during all the image acquisition.

The ultrasound scans were then analyzed using ImageJ (NIH, USA) image analysis software. Quadriceps muscle total area and vastus lateralis only area were measured following the muscle bellies borders, CSA: ICC $=0.99$, SEM $=0.85 \mathrm{~cm}^{2}$.

Peak knee extensors muscle force (QF) of the right leg was estimated from maximal voluntary isometric contraction (MVC) at a $90^{\circ}$ knee angle with hip fixed at $90^{\circ}$. Force was measured by an electrical transducer (TSD121C; BIOPAC Systems, BIOPAC Systems Inc., Goleta, CA, USA) with 1-kHz sampling frequency implemented on a custom-built chair for isometric contractions of knee extensor muscle groups. After familiarization, participants performed two $4 \mathrm{~s}$-MVCs with a 2-min rest between contractions. Subjects were provided with real time visual feedback of torque production during isometric contraction. The MVC with highest QF was considered for further analysis. QF maximal value then was normalized per quadriceps muscle area to obtain force per area $\left(\mathrm{N} \mathrm{x} \mathrm{cm}{ }^{2}\right) . \mathrm{MCV}$ : $\mathrm{ICC}=$ $0.098, \mathrm{SEM}=1.8 \mathrm{~N}$.

\section{Performance tests \\ Yo-yo intermittent recovery test level 1}

The Yo-yo Intermittent Recovery Test Level 1 (YYIR1) test was developed to measure an athlete's ability to repeatedly perform high-intensity aerobic work. Since then, it is one of the most commonly used aerobic field tests for youth and recreational athletes. It has been shown to be a valid and reliable predictor of high-intensity aerobic capacity and $\mathrm{VO}_{2}$ max amongst athletes from various sports and competition-levels [37]. The YYIR1 focuses on an individual's ability to repeatedly perform high-intensity aerobic work. Participants began the test from the "start line". When instructed by the audio player, they must run towards "turn-around line 2" (this must be reached before the following beep signal) and immediately return to the "start line" before the next signal. Once "start line" is reached, participants then have a 10-s recovery period in which they must jog from "start line" towards "turn- around line 1", and then back to "start line" before the commencement of the next shuttle. In this test the participants are only allowed two consecutive fail attempts before they are withdrawn from the test. That being, if the individual fails to reach "turn line 2" and back to "start line" in the allocated time, one fail is issued. If this happens a second consecutive time, then they are eliminated. Test-retest reliability for Yo-yo intermittent test obtained in our setting was consistent with previous findings: ICCr: Yo-yo test: 0.90, SEM: $1.3 \mathrm{~m}$ [38].

\section{Counter movement jump test $\mathrm{CMJ}$}

Counter movement jump test (CMJ) was performed on a contact mat (Ergojump- Bosco system, srl, S Rufina di Cittaducale, Rieti, Italia), that allowed the measurements of height of jump, time of flight and time of contact. The CMJ starting from standing position, then subjects were instructed to perform a rapid downward movement to about $90^{\circ}$ of knee flexion immediately followed by an upward movement. The subjects were requested to jump as high as possible. CMJ was performed three times with two minutes rest between each trial. The best performance was retained and included in the test. Test-retest reliability for CMJ obtained in our setting was consistent with previous findings: ICCr: CMJ 0.99, SEM: $0.95 \mathrm{~cm}$ [39].

\section{Statistical analysis}

Results are presented as mean and standard deviation (SD). An independent samples $t$ test was used to test baseline differences between groups. The two-way repeated-measures ANOVA was performed, with two levels by time (pre- and post-test) and considering groups (KD, WD) as inter-subject factor, in order to assess differences between groups over the course of the study (Graphpad Prism version n 4.00 for Mac, GraphPad software, San Diego, CA, USA and JASP http:// www.jasp-stats.org). All differences were considered significant at $P<0.05$ (95\% CI). Post-hoc analyses were performed using the Bonferroni test. In addition, effect size (ES) calculation was done with Cohen's $d$, as a standardized measurement based on SD differences; while $d=0.2$ was considered a small affect, $\mathrm{d}=0.5$ was medium effect and $\mathrm{d}=0.8$ was a large effect, it is used as a guide for substantive significance. The normal Gaussian distribution of the data was verified by the Shapiro-Wilk test. An unpaired t-test with Welch's correction were performed when appropriate.

\section{Results}

\section{Dietary nutrition intake}

There were no differences in dietary nutrient intakes between groups at baseline. Subjects adhered very well with the given instructions for both diet interventions according to analysis of diets records (3 days food-diary before 
Table 3 Daily intake of dietary energy and nutrients at baseline and during ketogenic diet (KD) and Western Diet (WD)

\begin{tabular}{|c|c|c|c|c|c|c|c|c|c|}
\hline & KD PRE & KD POST & $\begin{array}{l}\% \\
\text { changes }\end{array}$ & WD PRE & WD POST & $\begin{array}{l}\% \\
\text { changes }\end{array}$ & $\begin{array}{l}2 \text { Way ANOVA } \\
\text { Time*Diet }\end{array}$ & $\begin{array}{l}\text { Main Time } \\
\text { effect }\end{array}$ & $\begin{array}{l}\text { Main diet } \\
\text { effect }\end{array}$ \\
\hline Total (Kcal/day) & $2356 \pm 450$ & $1984 \pm 430$ & -15.78 & $2146 \pm 230$ & $1752 \pm 320$ & -18.35 & n.s. & $<0.001$ & n.s. \\
\hline $\mathrm{CHO}$ (g/day) & $350 \pm 66$ & $22 \pm 5$ & -93.71 & $363 \pm 34$ & $220 \pm 56$ & -39.39 & $<0.0001$ & $<0.0001$ & $<0.0001$ \\
\hline PRO (g/day) & $105 \pm 20$ & $130 \pm 25$ & +23.81 & $121 \pm 23$ & $129 \pm 28$ & +.6 .61 & n.s & n.s. & n.s. \\
\hline FAT (g/day) & $107 \pm 20$ & $132 \pm 27$ & +23.36 & $110 \pm 16$ & $38 \pm 10$ & -65.45 & n.s. & $<0.001$ & n.s. \\
\hline $\mathrm{CHO}(\%)$ & $49 \pm 6$ & $9 \pm 3$ & -81.63 & $51 \pm 4$ & $51 \pm 4$ & 0 & $<0.0001$ & $<0.0001$ & $<0.0001$ \\
\hline PRO (\%) & $15 \pm 3$ & $28 \pm 4$ & +86.66 & $14 \pm 6$ & $28 \pm 3$ & +100 & n.s. & $<0.0001$ & n.s. \\
\hline FAT (\%) & $35 \pm 4$ & $64 \pm 3$ & +82.85 & $33 \pm 2$ & $20 \pm 8$ & -39.39 & $<0.0001$ & $<0.0001$ & $<0.0001$ \\
\hline PRO (g/kg bw/day) & $1.37 \pm 0.5$ & $1.85 \pm 0.3$ & +35.03 & $1.59 \pm 0.4$ & $1.83 \pm 0.2$ & +15.09 & n.s. & $=0.0098$ & n.s. \\
\hline Saturated fat (g) & $35 \pm 10$ & $45 \pm 12$ & +28.57 & $36 \pm 4$ & $15 \pm 3$ & -58.33 & $<0.0001$ & n.s. & $<0.0001$ \\
\hline $\begin{array}{l}\text { Monounsaturated } \\
\text { fat }(\mathrm{g})\end{array}$ & $28 \pm 6$ & $49 \pm 16$ & +75 & $27 \pm 5$ & $9 \pm 5$ & -66.66 & $<0.0001$ & n.s. & $<0.0001$ \\
\hline $\begin{array}{l}\text { Polyunsaturated fat } \\
\text { (g) }\end{array}$ & $16 \pm 3$ & $21 \pm 5$ & +23.80 & $16 \pm 9$ & $5 \pm 2$ & -68.75 & $=0.0003$ & n.s & $=0.0003$ \\
\hline Cholesterol (mg) & $304 \pm 101$ & $720 \pm 4187$ & +136.84 & $303 \pm 98$ & $167 \pm 65$ & -44.88 & $<0.0001$ & $=0.0029$ & $<0.0001$ \\
\hline Fibers (g) & $13 \pm 2$ & $10 \pm 3$ & -23.07 & $11 \pm 9$ & $15 \pm 4$ & +36.36 & n.s & n.s. & n.s. \\
\hline
\end{tabular}

Values are mean $\pm S D$, Analysis performed on 3 days of diet records during baseline (habitual diet) and 7 days during the KD and WD

the study and 7 days food-diary during the study). During the diet interventions, as planned, carbohydrate intake was significantly lower and fat intake significantly higher in the KD. Total dietary energy intake was reduced during both diet without significant difference $(K D=1.984 \pm$ $340 \mathrm{Kcal} /$ day; $\mathrm{WD}=1.752 \pm 320 \mathrm{Kcal} /$ day. Importantly, protein intake, calculated both as energy percentage and grams of protein per kilogram of body weight, was similar in the two groups (Table 3).

All subjects achieved the full ketogenic metabolic adjustment as indicated by color changes on the urinary reagent strips (pink-violet i.e. about $1.5 \mathrm{mmol} / \mathrm{L} \mathrm{KBs)}$ and by capillary blood ketones levels (mean $1.3 \pm 0.4$ $\mathrm{mmol} / \mathrm{L}$ throughout the 4 weeks). These data indicate a good compliance to the carbohydrate restriction (Fig. 2).

Body composition, resting energy expenditure, respiratory exchange ratio, cross sectional area, strength test, performance tests

The reduction of body fat $(-1.55 \mathrm{Kg} \mathrm{KD}$ vs $-0.92 \mathrm{Kg}$ WD; time *diet interaction $p=0.0359)$, visceral adipose tissue VAT $(-63 \mathrm{~g}$ KD vs $-27 \mathrm{~g}$ WD; time "diet

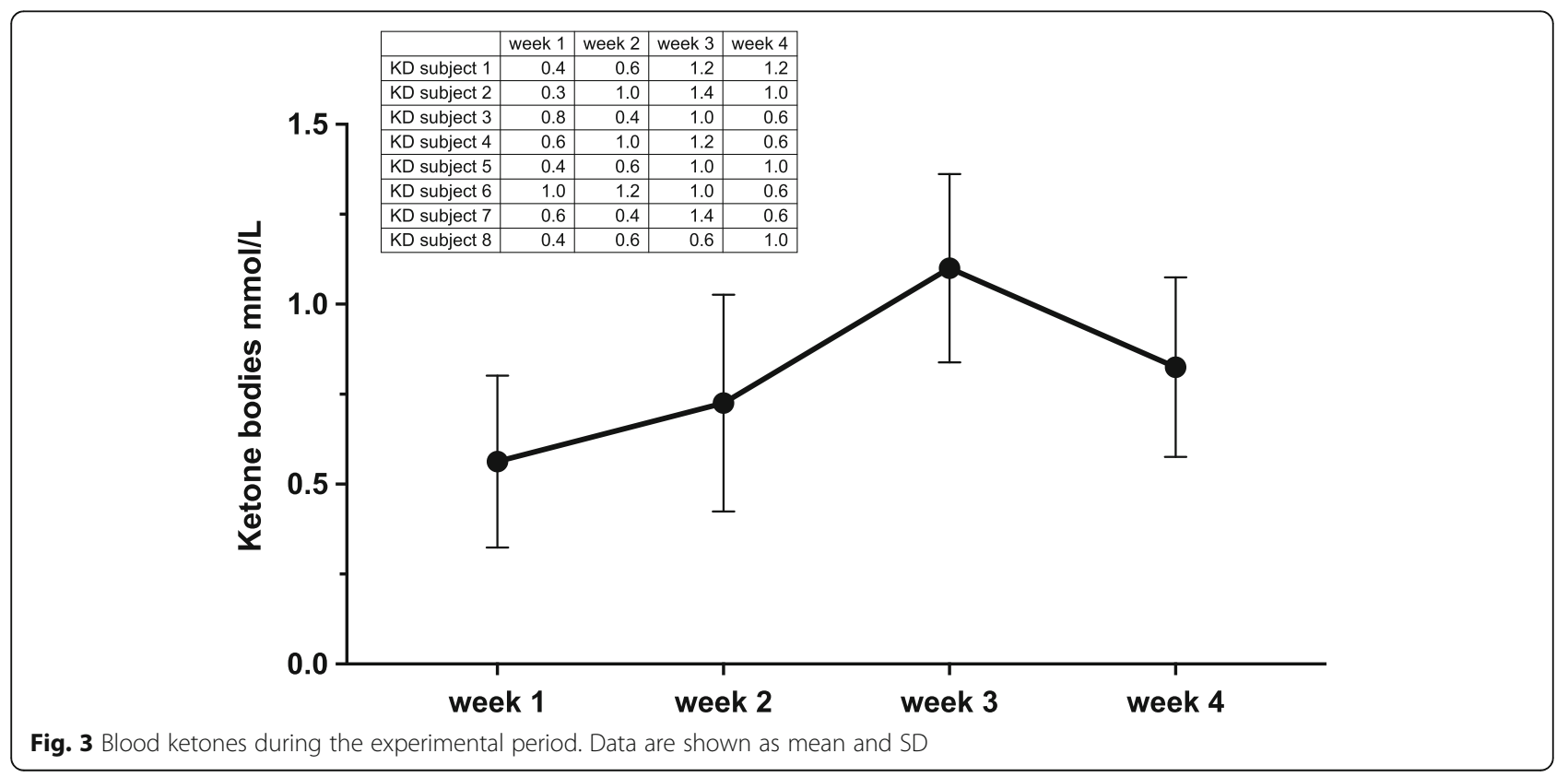


interaction $p=0.0018)$, waist circumference $(-4.19 \mathrm{~cm}$ KD vs $-1.38 \mathrm{~cm}$ WD; time *diet interaction $p=0.0185$ ), extra cellular water $(-3.43 \% \mathrm{KD}$ vs $0.03 \% \mathrm{WD}$; time "diet interaction $p=0.0060$ ) were significantly greater in KD group than in WD group. Body weight decreased significantly in both groups without significant differences between groups.. Soft lean tissue mass was substantially maintained constant in both groups, as well as all hydration parameters: total body water (TBW), intracellular water $(\mathrm{ICW})$, extracellular water $(\mathrm{ECW})$. Moreover, no significant changes were detected in dry lean soft tissue (DLST) calculated as lean soft tissue (LST) minus TBW, and in LST hydration calculated as TBW/ LST [40]. No differences were detected in appendicular nor in trunk LST measured by DXA. Diastolic blood pressure decreased significantly in both group (with a greater $\Delta$ pre vs post of $6 \mathrm{mmHg}$ in KD, ES: Cohen's $d$ : 1.07, simple main effect $\left.\mathrm{KD} ; \mathrm{P}_{\text {bonf }}<0.001\right)$. Quadriceps muscle area and maximal strength were maintained in both groups. There were no changes for absolute and relative $(\mathrm{Kcal} / \mathrm{Kg}) \mathrm{REE}$ in both groups even though $\mathrm{KD}$ showed a greater $\Delta$ pre vs post difference $=1.32 \mathrm{Kcal} /$ $\mathrm{Kgbw} /$ day, ES: Cohen's $d$ : 0.6, simple main effect KD; $\mathrm{P}_{\text {bonf }}<0.001$ ), whilst RER decreased significantly in KD (time "diet interaction $p=0.0008$ ), further indicating a good compliance to KD diet. (Fig. 3) Yo-yo intermittent test and CMJ improved significantly $(p<0.001)$ in both groups without differences between groups.

\section{Discussion}

To the best of our knowledge, this is the first study investigating the effects of a KD on performance in team sport, like soccer. Although many strategies are available for athletes aiming to reduce weight, the majority of those are not without risks and are not universally effective for all athletes. In our study, a team of semiprofessional soccer players underwent a significant reduction in body weight, body fat mass, waist circumference, visceral adipose tissues (VAT) and extra cellular water $(\mathrm{ECW})$ without negative effects on strength, power and muscle mass. Our data, in contrast to other studies $[16,18]$, showed no deleterious effects of KD on sport performance nor an improvement [19, 21]. Substantially our data suggest no effects of a KD on soccer-related performance tests. These conflicting results could be explained by several factors:

1) necessity to keep diet at least for 5-6 days, that is the time needed for keto-adaptation (as suggested in a recent paper [41];

2) electrolytes supplementation;

3) adequate protein intake in terms of quantity, quality and timing;

4) adequate hydration [12].
In our study the ketogenic phase was kept for 30 days, the duration of the diet was chosed on the bases of previous published researches [16, 18, 42-44]. As suggested by Burke and colleagues $5-6$ days are enough to reach an adaptation [41] and could be defined as brief or short-term adaptation whilst 30 days could be defined as medium KD adaptation [41, 45] Adequate supplementation containing sodium and potassium in a form of plant extract, and magnesium was included. This aspect allowed to keep an healthy electrolytic balance with an adequate intake of minerals and vitamins, which is really essentials to preserve the functions of tissues [28]. It is known that micronutrients play an important role in energy production, hemoglobin synthesis, bone health, immune system and protection from oxidative stress [46]. Actually, these supplementations are not fundamental for athletes who eat an adequate quantity and good quality of foods, however, during period of low-caloric diet or unbalanced diet, such as ketogenic diet, a supplementation with minerals and vitamins may be useful to improve nutritional status and athletic performance [46]. In our study the athletes enrolled in the KD group were able to maintain their lean soft tissue. One of the reasons for this result may rely on the adequate amount of protein intake: indeed, we calculated the protein intake of the subjects according to the last evidence issued from International Society of Sport Nutrition (ISSN) [32]. Protein intake was distributed equally throughout the day (every 3-4h): KD was provided with high protein substitutive meals (RKP), whilst WD ate high protein foods as cottage cheese, egg white, bresaola or whey protein.

Pre-sleep casein protein intake (30-40 g) was provided in both group after training evening session, as indicated by ISSN [32]. Moreover, considering that in sports field the prevention of loss of skeletal muscle during acute inflammation is fundamental, KD could be a tool to reduce inflammation [30, 47] and therefore preserve muscle mass [48]. Lastly, both groups were provided of an adequate intake of water, in order to avoid dehydration, a condition that has detrimental effects and lead to a great reduction in performance. The maintenance of strength and power performance deserves close attention. It has already been demonstrated that a 30-days of KD did not negatively affect explosive and strength performance in a group of high-level gymnasts [19], and, these positive result reflected the high intake of proteins, $\left(\sim 40 \%\right.$ daily intake $\left.\left(130 \pm 25 \mathrm{~g} \mathrm{x}_{\text {day }}{ }^{-1}\right)\right)$. In this study, strength and lean soft tissue were maintained even though the daily intake of protein was lower: we provided $1.8 \mathrm{~g} \mathrm{x} \mathrm{Kg}^{-1}$ x body weight ${ }^{-1}(\sim 25-30 \%$ protein daily intake) in both groups. The fundamental point is that an inadequate protein intake would be likely to negatively affect performance. Even with this amount of 
protein though, the players showed a decrease in body mass and a maintenance of muscle mass, as a result of the well-known "muscle- sparing effect", which occurs after a few days of ketosis [12]. During ketosis, the use of KBs and FFAs for energy production reduces gluconeogenesis that is related to an increased muscle protein catabolism and therefore, preserves muscle mass. Moreover, the relative increase of dietary amino-acid intake stimulates protein synthesis effect via mTOR signaling pathways [49] and it has been proposed as key factor for the preservation of lean soft tissue during KD [50] together with the anticatabolic effect in skeletal muscle given by the pleiotropic effects of ketone bodies on gene expression in muscle mass, inflammation and oxidative stress [51].. Recent studies have shown a preservation of strength in individuals on low carbohydrate diets [21, 52-54], nevertheless, dietary strategies involving carbohydrate restriction have been considered potentially able to compromise strength and power performance on longer term, as a result of diet-induced glycogen depletion [55]. The restoration of muscle glycogen by means of carbohydrate ingestion is obviously important for athletes and should not be neglected. On the other hand, KD may interfere with some muscle molecular (IGF-1, mTOR, AKT etc.) [50] and hormonal mechanisms (during the ketogenic period insulin, a powerful anabolic hormone, remains at very low levels, around $7 \mathrm{mU} / \mathrm{L}$ ) related to skeletal muscle hypertrophy processes. The net balance, as suggested by recent research, seems to be the maintaining of muscle mass but a blunted hypertrophy response [54]. For athletes, the nutrients intake strategy should be tailored to the functional needs of the particular sport and, perhaps even more specifically, to the particular positional requirements within a sport and the individual needs of the athlete. One of the most striking result of the study was the ability of players to maintain their level of training and performance. This is in contradiction with the results of studies showed a decreased in performance after 10 weeks [56], 3 weeks [16], or 7 days or less of carbohydrate restricted diets [57]. This may be explained by the different subjects we investigated, indeed, for the first time, athletes of team sport were studied under a KD protocol, whilst previous studies studied mainly endurance athletes or strength/ power athletes. Moreover, it should be noticed that the increasing in the Yo-Yo and $\mathrm{CMJ}$ in both groups from pre to post intervention, may be reasonably due to the reduction of total body mass and to the maintenance of lean soft tissue (as showed by DXA, CSA and strength) which, in turn, has improved the power/body weight ratio $[19,58]$. As regard weight loss, the evidences supporting it, are certainly strong [59] and as described previously, many factors seem to be involved [60]. One suggested reason for a greater weight loss during a KD is its anorexigenic effects and hence, a reduction of daily energy intake; this was not the case of our study whereas energy intake was equivalent between the two groups. Other candidate for the greater fat loss is the increase in REE. As a matter of fact the question is still under debate: there are data suggesting that the fat loss induced by a ketogenic diet relies only on calorie deficit [61] whilst other researchers claim that KD induces an increase of REE [62, 63]. This metabolic advantage may occur during a KD due to the demand on protein turnover for gluconeogenesis, greater thermogenic effect of protein and loss of energy as heat, and/or excretion of energy in the form of ketones via urine, feces, and/or sweat. Notably, we reported no significant effect of time * diet interaction in REE (in absolute terms and weightadjusted), after 30 days of $\mathrm{KD}$. It has to be underline, however, that calculating the simple main effect for diet in KD group showed a significative result in adjusted REE ( $\mathrm{P}_{\text {bonf }}<0.001$ with an ES Cohen's $d$ : 0.6). Moreover our data support the idea that an adequate intake of protein facilitates weight loss, in part, by preserving the basal metabolic rate. It is known that fat free mass is the major determinant of REE [64] and, in our study, it has been maintained in both groups. As previously pointed out, the body has a great capacity to adapt substrate oxidation to substrate intake after approximately 1 week of carbohydrate and fats, in our study fat oxidation increased, as an adaptation to the high-fat intake, typical of KD. RER decreased dramatically reflecting both the reduction in lipid synthesis and increased lipolysis mechanisms and an increase in fat metabolism for energy use. Considering the isocaloric diet, the same training protocols, and the absence of significative difference of REE's change between groups, the measured greater fat loss in the KD deserves few more words. Our data confirmed previous findings from our group [36] and other groups [65] about the lack of a significant increase of REE during short term KD compared to a WD in training individual. However, in our study, REE in KD group showed a greater ES compared to WD. This little REE increase $(1.32 \mathrm{Kcal} / \mathrm{Kg}$ bw/day; $5.47 \%)$ may explain findings from other researchers showing a significant effect of KD on REE and thus a greater weight loss during more long intervention studies [66]. Caloric intake showed no significant difference between the two groups (as showed in Table 4), even though the total dietary energy intake was slightly higher (although not significant) during $\mathrm{KD}$ $(1.984 \pm 340 \mathrm{Kcal} /$ day $)$ compared to WD $(1.752 \pm$ $320 \mathrm{Kcal} /$ day). One another possible explanation of the greater fat loss in the KD, apart from the little increase of REE, may rely to an increased spontaneous physical activity during the day as suggested by Hall and colleagues "... such outpatient weight loss diets may lead to greater body fat loss because of decreased energy intake 
Table 4 Body composition, metabolic and performance values. Data are reported as mean plus SD and percentage of change

\begin{tabular}{|c|c|c|c|c|c|c|c|c|c|}
\hline & KD PRE & KD POST & $\begin{array}{l}\% \\
\text { changes }\end{array}$ & WD PRE & WD POST & $\begin{array}{l}\% \\
\text { changes }\end{array}$ & $\begin{array}{l}2 \text { Way ANOVA } \\
\text { Time*Diet }\end{array}$ & $\begin{array}{l}\text { Main Time } \\
\text { effect }\end{array}$ & $\begin{array}{l}\text { Main diet } \\
\text { effect }\end{array}$ \\
\hline Body Weight (Kg) & $78.19 \pm 11.74$ & $73.98 \pm 9.40$ & -5.12 & $76.15 \pm 12.03$ & $73.76 \pm 10.13$ & -2.87 & n.s. & $<0.001$ & n.s. \\
\hline FM (Kg) & $19.47 \pm 4.07$ & $17.92 \pm 3.81$ & -7.93 & $18.88 \pm 6.67$ & $17.96 \pm 6.30$ & $-4-92$ & 0.036 & $<0.001$ & n.s. \\
\hline VAT (g) & $388 \pm 66$ & $325 \pm 54$ & -16.03 & $355 \pm 104$ & $328 \pm 101$ & -7.99 & 0.0018 & $<0.0001$ & n.s. \\
\hline TRUNK fat (\%) & $25.73 \pm 3.90$ & $24.04 \pm 3.79$ & -6.63 & $24.45 \pm 4.57$ & $23.18 \pm 4.37$ & -5.21 & n.s. & $<0.001$ & n.s. \\
\hline LST (Kg) & $57.4 \pm 7.10$ & $56.9 \pm 7.01$ & -0.87 & $56.21 \pm 5.94$ & $56.019 \pm 5.72$ & -0.34 & n.s. & $<0.001$ & n.s. \\
\hline $\mathrm{pHa}\left({ }^{\circ}\right)$ & $7.4 \pm 0.64$ & $7.8 \pm 0.66$ & +5.63 & $7.32 \pm 0.39$ & $7.31 \pm 0.45$ & -0.17 & 0.003 & $=0.005$ & n.s. \\
\hline ECW (\%) & $40.11 \pm 2.25$ & $38.68 \pm 2.10$ & -3.56 & $40.35 \pm 1.22$ & $40.38 \pm 1.79$ & +0.05 & 0.0060 & $=0.008$ & n.s. \\
\hline ECW (L) & $19.93 \pm 3.39$ & $18.99 \pm 2.63$ & -4.26 & $19.75 \pm 2.96$ & $19.58 \pm 2.97$ & -0.91 & n.s. & $=0.017$ & n.s. \\
\hline TBW (L) & $49.79 \pm 6.43$ & $48.80 \pm 5.39$ & -1.76 & $48.84 \pm 6.55$ & $48.31 \pm 6.47$ & -1 & n.s. & n.s. & n.s \\
\hline ICW (L) & $29.8 \pm 3.51$ & $29.78 \pm 3.33$ & +0.1 & $29.49 \pm 3.69$ & $29.15 \pm 3.74$ & -1.03 & n.s. & n.s. & n.s. \\
\hline DLST (Kg) & $7.58 \pm 1.85$ & $8.09 \pm 2.08$ & +7.28 & $6.96 \pm 1.68$ & $7.65 \pm 1.98$ & +16.75 & n.s. & n.s. & n.s. \\
\hline LST Hydr \% & $86.72 \pm 2.68$ & $85.91 \pm 2.69$ & -0.9 & $86.68 \pm 2.95$ & $86.08 \pm 3.56$ & -0.67 & n.s. & n.s & n.s. \\
\hline LST L arm (Kg) & $3.25 \pm 0.55$ & $3.33 \pm 0.47$ & +2.82 & $3.25 \pm 0.4$ & $3.39 \pm 0.61$ & +4.53 & n.s. & n.s & n.s. \\
\hline LST R arm (Kg) & $3.2 \pm 0.4$ & $3.19 \pm 0.39$ & -0.33 & $3.28 \pm 0.54$ & $3.27 \pm 0.4$ & -0.38 & n.s. & n.s & n.s. \\
\hline LST L leg (Kg) & $9.31 \pm 1.66$ & $9.43 \pm 1.5$ & +2.58 & $9.61 \pm 1.22$ & $9.04 \pm 1.26$ & -5.67 & n.s. & n.s & n.s. \\
\hline LST R leg (Kg) & $9.33 \pm 1.4$ & $10.4 \pm 1.77$ & +8.15 & $9.74 \pm 1.24$ & $9.25 \pm 1.32$ & -4.79 & n.s. & n.s & n.s. \\
\hline LST Trunk (Kg) & $28.04 \pm 4.49$ & $26.38 \pm 2.99$ & -5.3 & $26.61 \pm 2.78$ & $27.08 \pm 3.19$ & +1.91 & n.s. & n.s & n.s. \\
\hline DBP & $77.5 \pm 4.10$ & $72.88 \pm 4.51$ & -6.0 & $78.8 \pm 6.7$ & $75.88 \pm 5.93$ & -3.71 & n.s. & $<0.001$ & n.s. \\
\hline $\begin{array}{l}\text { Waist } \\
\text { circumference } \\
(\mathrm{cm})\end{array}$ & $86.75 \pm 4.97$ & $82.56 \pm 3.61$ & -4.74 & $83.63 \pm 8.66$ & $82.25 \pm 6.86$ & -1.48 & 0.0185 & $<0.001$ & n.s. \\
\hline $\mathrm{CSA}(\mathrm{cm} 2)$ & $71.83 \pm 8.32$ & $72.20 \pm 6.53$ & +0.87 & $71.05 \pm 9.88$ & $71.29 \pm 9.247$ & -0.53 & n.s & n.s. & n.s. \\
\hline $\mathrm{MCV}(\mathrm{N})$ & $628.9 \pm 163.3$ & $617.3 \pm 150.2$ & -0.63 & $621.3 \pm 99.11$ & $596.0 \pm 95.56$ & -3.63 & n.s & n.s. & n.s. \\
\hline Strenght/CSA & $8.754 \pm 1.966$ & $8.515 \pm 1.628$ & -1.04 & $8.794 \pm 1.220$ & $8.472 \pm 1.697$ & -4.19 & n.s. & n.s. & n.s. \\
\hline RER & $0.87 \pm 0.08$ & $0.74 \pm 0.04$ & -14.18 & $0.85 \pm 0.04$ & $0.83 \pm 0.03$ & -2.85 & 0.0008 & $<0.001$ & n.s. \\
\hline REE (Kcal/day) & $1940 \pm 138.9$ & $1939 \pm 137$ & $=$ & $1916 \pm 140.8$ & $1917 \pm 136.3$ & +0.05 & n.s & n.s. & n.s. \\
\hline $\begin{array}{l}\text { REE (Kcal/Kg bw/ } \\
\text { day) }\end{array}$ & $23.4 \pm 0.8$ & $23.3 \pm 0.8$ & +5.47 & $22.3 \pm 1.0$ & $22.4 \pm 0.8$ & +3.05 & n.s & $<0.001$ & n.s. \\
\hline Yo-yo (m) & $880.4 \pm 244.8$ & $1123 \pm 266.8$ & +28.04 & $683.0 \pm 388.1$ & $911.1 \pm 378.5$ & +44.62 & n.s & $<0.001$ & n.s. \\
\hline $\mathrm{CMJ}(\mathrm{cm})$ & $40.4 \pm 6.5$ & $43.6 \pm 6$ & +8.52 & $37.3 \pm 2.9$ & $38.6 \pm 04.1$ & +3.60 & n.s & $<0.001$ & n.s. \\
\hline
\end{tabular}

Values are mean \pm SD

$n . s$. not statistically different $(p>0.05)$

The percentage of change was calculate through the following formula [(initial value/final value)/initial value] ${ }^{*} 100 . F M$ fat mass, VAT visceral adipose tissue, $L S T$ lean soft tissue, pHa, ECW extra cellular water, TBW total body water, ICW intracellular water, DLST dry lean soft tissue, $L S T$ Hydr lean soft tissue hydration, DBP blood pressure, CSA cross sectional area, $M C V$ maximal voluntary contraction, $R E R$ respiratory exchange ratio, $R E E$ resting energy expenditure, $C M J$ counter movement jump, $\mathrm{mmHg}$ millimeters of Mercury, $L$ left, $R$ right. DLST was calculated as LST-TBW; LST Hydr was calculated as TBW/LST

and/or increased physical activity" [67] that we unfortunately didn't measured.

Regarding VAT, the majority of the published researches on KD and VAT were on persons with obesity [68-73], whilst only one previous study investigate the effect of KD on VAT in trained males [21]. Our data confirm the KD exerts a positive effect on VAT not only in persons with obesity but also in athletes.

VAT accumulation is associated with multiple cardiovascular disease (CVD) risk factors, including hypertension, impaired fasting glucose, type 2 diabetes, metabolic syndrome and low-grade chronic inflammation [74]. In athletes the reduction of the latest is of paramount importance to reduce injury risk and to improve recovery [75].

Some limits need to be considered. With regard to body composition's analysis, a consideration should be done: as emerged from our study, both groups lost a significant amount of visceral fat measured by DXA, however, it has to be considered that DXA is an indirect approach with potential errors due to the fluid changes and hydration status of individuals [76]. For this reason, we checked hydration values demonstrating no significant changes in LST hydration. 
Another limit of our research is the low sample number due to the common problem of recruiting athletes playing in sport team for experimental protocol during the competitive season. To minimize the burden on subjects, tests were performed at only at 2 time points, (beginning and end of the study), thus ketonemia was measured twice a week. Further limit could be the absence of blood exams such as pro-inflammatory cytokines; we decided to not perform hematological exams to increase adherence of athletes and in consideration of the fact that many papers have been already published about the effects of KDs on these variables.

Finally, since adherence to KD may be hard to be maintained for long periods due to the lack of some basic foods (i.e.: pasta, rice, sweets) and extrasupplements may be not always available for athletes, a specific and more accurate protocol based on convenience foods could be potentially developed in order to facilitate adherence to the KD. Moreover, a ketogenic diet can be vegetarian or vegan, with plant-based fats (i.e.., avocado, nuts, seeds, coconut, olive oil), proteins (i.e., tofu, tempeh, seitan, pea protein, veggie bacon), nonstarchy vegetables, and limited amounts of low-sugar fruits (i.e.: berries, lime, lemon, kiwis). This kind of "flexibility" allows practitioners to targeting and personalizing dietary choice on a KD. A fundamental point that can be also considered is that subjects in KD received specific plant extracts in a minimum dosage to increase the daily intake of fluid, however, the dosage was very low and could not be counted as supplements able to induce some extra effects.

\section{Conclusions}

A common objective for many soccer players is to lose body fat while gaining or maintaining muscle mass, strength and power, although the time periods for such gains and losses are infrequent and often short.

There are several options available to lose fat. Regarding the well-known and discussed principle of energy balance, one option is to reduce energy intake by up $1000 \mathrm{Kcal} /$ day per week, but, this method may take longer to achieve weight loss goals and when energy intake is restricted, it is important to acknowledge the corresponding decrease in protein ingestion. An inadequate protein ingestion leads to negative effects on athletic performance, mood, perception of fatigue and decrease in lean soft tissue. Current protein intake guidelines for athletes suggest, for an average individual of $70 \mathrm{Kg}$ of body weight, around $120 \mathrm{~g}$ of protein adequately distributed throughout the day [32]. In our study, we demonstrate that KD could be a safe and feasible strategy to lose fat mass in a short term, without impairing strength, power and muscle mass in a team sport like soccer.
Additionally, the greater reduction in VAT during KD in athletes represents a novel significant finding that deserve further investigation in higher categories soccer athletes. When the goal is a rapid weight loss reduction, coaches and athletes should consider the use of KD as a feasible and safe tool also in team sports.

\section{Acknowledgements \\ Authors would like to thank all the athletes participating to the experiment. \\ Authors' contributions \\ AP, LM and GM conceived and drawn the experiment, LM and DG collected the data, EM collected muscle morphological data, MVN and EM analyzed muscle morphological data, LM, LM and LC designed the nutritional protocol, FP contribute to the discussion, MP supervised the training and tests protocols, MC revised critically the manuscript. AP and LM wrote the manuscript. All authors read and approved the final manuscript.}

\section{Funding}

The research was funded with intramural grants.

\section{Availability of data and materials}

The datasets used and/or analysed during the current study are available from the corresponding author on reasonable request.

\section{Declarations}

\section{Ethics approval and consent to participate}

All the subjects read and signed the informed consent document with the description of the testing procedures approved by the ethical committee of the Department of Biomedical Sciences, University of Padova, and conformed to standards for the use of human subjects in research as outlined in the Declaration of Helsinki.

\section{Consent for publication}

Not applicable.

\section{Competing interests}

The authors declare that they have no competing interests.

\section{Author details}

${ }^{1}$ Department of Biomedical Sciences, University of Padua, Via Marzolo, 3 , 35131 Padua, Italy. ${ }^{2}$ Research Center for High Performance Sport, UCAM, Catholic University of Murcia, 30107 Murcia, Spain. ${ }^{3}$ Human Inspired

Technology Research Center, University of Padua, Padua, Italy. ${ }^{4}$ Department of Human Sciences and Promotion of the Quality of Life, San Raffaele Roma Open University, Rome, Italy. ${ }^{5}$ Italian Microbiome Project, Milan, Italy. ${ }^{6}$ Inter FC., Milan, Italy. ${ }^{7}$ FIGC Federazione Italiana Giuoco Calcio (Italian Football Federation), Rome, Italy.

Received: 17 June 2020 Accepted: 25 August 2021

Published online: 16 September 2021

\section{References}

1. Dvorak J, Junge A, Graf-Baumann T, Peterson L. Football is the most popular sport worldwide. Am J Sports Med. 2004;32(1 Suppl):3S-4S. https://doi.org/1 $0.1177 / 0363546503262283$.

2. Russell M, Kingsley M. Influence of exercise on skill proficiency in soccer. Sports Med. 2011;41(7):523-39. https://doi.org/10.2165/11589130000000000-00000

3. Sutton L, Scott M, Wallace J, Reilly T. Body composition of English premier league soccer players: influence of playing position, international status, and ethnicity. J Sports Sci. 2009;27(10):1019-26. https://doi.org/10.1080/0264041 0903030305.

4. Statistics from Italian football [https://www.figc.it/en/figc/mission-andgovernance/statistics-from-italian-football/].

5. Oliveira CC, Ferreira D, Caetano C, Granja D, Pinto R,Mendes B, et al. Nutrition and Supplementation in Soccer. Sports(Basel). 2017;5(2):28. https:// doi.org/10.3390/sports5020028. 
6. Ackland TR, Lohman TG, Sundgot-Borgen J, Maughan RJ, Meyer NL, Stewart $A D$, et al. Current status of body composition assessment in sport: review and position statement on behalf of the ad hoc research working group on body composition health and performance, under the auspices of the I.O.C. medical commission. Sports Med. 2012;42(3):227-49. https://doi.org/10.21 65/11597140-000000000-00000

7. Steffl M, Kinkorova I, Kokstejn J, Petr M. Macronutrient Intake in Soccer Players-A Meta-Analysis. Nutrients. 2019;11(6):1305. https://doi.org/10.3390/ nu11061305.

8. Heaton LE, Davis JK, Rawson ES, Nuccio RP, Witard OC, Stein KW, et al. Selected in-season nutritional strategies to enhance recovery for team sport athletes: a practical overview. Sports Med. 2017;47(11):2201-18. https://doi. org/10.1007/s40279-017-0759-2

9. Williams C, Rollo I. Carbohydrate nutrition and team sport performance. Sports Med. 2015;45(Suppl 1):S13-22.

10. Carling C, Orhant E. Variation in body composition in professional soccer players: interseasonal and intraseasonal changes and the effects of exposure time and player position. J Strength Cond Res. 2010;24(5):1332-9. https:// doi.org/10.1519/JSC.0b013e3181cc6154.

11. Turocy PS, DePalma BF, Horswill CA, Laquale KM, Martin TJ, Perry AC, et al. National Athletic Trainers a: National Athletic Trainers' association position statement: safe weight loss and maintenance practices in sport and exercise. J Athl Train. 2011;46(3):322-36. https://doi.org/10.4085/1062-6050-4 6.3.322.

12. Paoli A, Bianco A, Grimaldi KA. The ketogenic diet and sport: a possible marriage? Exerc Sport Sci Rev. 2015;43(3):153-62. https://doi.org/10.1249/ JES.0000000000000050

13. Krebs HA. The regulation of the release of ketone bodies by the liver. Adv Enzym Regul. 1966;4:339-54. https://doi.org/10.1016/0065-2571(66)90027-6.

14. Cahill GF Jr. Fuel metabolism in starvation. Annu Rev Nutr. 2006;26(1):1-22 https://doi.org/10.1146/annurev.nutr.26.061505.111258.

15. Evans $M$, Cogan KE, Egan B. Metabolism of ketone bodies during exercise and training: physiological basis for exogenous supplementation. J Physiol. 2017;595(9):2857-71. https://doi.org/10.1113/JP273185.

16. Burke LM, Ross ML, Garvican-Lewis LA, Welvaert M, Heikura IA, Forbes SG, et al. Low carbohydrate, high fat diet impairs exercise economy and negates the performance benefit from intensified training in elite race walkers. J Physiol. 2017;595(9):2785-807. https://doi.org/10.1113/JP273230.

17. Kiens B, Astrup A. Ketogenic diets for fat loss and exercise performance: benefits and safety? Exerc Sport Sci Rev. 2015;43(3):109. https://doi.org/1 0.1249/JES.0000000000000053.

18. Shaw DM, Merien F, Braakhuis A, Maunder ED, Dulson DK. Effect of a ketogenic diet on submaximal exercise capacity and efficiency in runners. Med Sci Sports Exerc. 2019;51(10):2135-46. https://doi.org/10.1249/MSS. 0000000000002008.

19. Paoli A, Grimaldi K, D'Agostino D, Cenci L, Moro T, Bianco A, et al. Ketogenic diet does not affect strength performance in elite artistic gymnasts. J Int Soc Sports Nutr. 2012;9(1):34. https://doi.org/10.1186/1550-2783-9-34.

20. Zajac A, Poprzecki S, Maszczyk A, Czuba M, Michalczyk M, Zydek G. The effects of a ketogenic diet on exercise metabolism and physical performance in off-road cyclists. Nutrients. 2014;6(7):2493-508. https://doi. org/10.3390/nu6072493.

21. Greene DA, Varley BJ, Hartwig TB, Chapman P, Rigney M. A low-carbohydrate ketogenic diet reduces body mass without compromising performance in powerlifting and Olympic weightlifting athletes. J Strength Cond Res. 2018; 32(12):3373-82. https://doi.org/10.1519/JSC.0000000000002904.

22. Vargas S, Romance R, Petro JL, Bonilla DA, Galancho I, Espinar S, et al. Efficacy of ketogenic diet on body composition during resistance training in trained men: a randomized controlled trial. J Int Soc Sports Nutr. 2018;15(1): 31. https://doi.org/10.1186/s12970-018-0236-9.

23. Volek JS, Freidenreich DJ, Saenz C, Kunces LJ, Creighton BC, Bartley JM, et al. Metabolic characteristics of keto-adapted ultra-endurance runners. Metabolism. 2016;65(3):100-10. https://doi.org/10.1016/j.metabol.2015.10. 028.

24. Cipryan L, Plews DJ, Ferretti A, Maffetone PB, Laursen PB. Effects of a 4-week very low-carbohydrate diet on high-intensity interval training responses. J Sports Sci Med. 2018;17(2):259-68

25. Paoli A, Bianco A, Grimaldi KA, Lodi A, Bosco G. Long term successful weight loss with a combination biphasic ketogenic mediterranean diet and mediterranean diet maintenance protocol. Nutrients. 2013:5(12):5205-17. https://doi.org/10.3390/nu5125205.
26. Leone A, De Amicis R, Lessa C, Tagliabue A, TrentaniC, Ferraris C, et al. Food and Food Products on theltalian Market for Ketogenic Dietary Treatment of Neurological Diseases. Nutrients. 2019;11(5):1104. https://doi.org/10.3390/ nu11051104

27. Lodi A, Karsten B, Bosco G, Gomez-Lopez M, Brandao PP, Bianco A, et al. The effects of different high-protein low-carbohydrates proprietary foods on blood sugar in healthy subjects. J Med Food. 2016;19(11):1085-95. https:// doi.org/10.1089/jmf.2016.0072.

28. Phinney SD. Ketogenic diets and physical performance. Nutr Metab (Lond). 2004;1 (1):2. https://doi.org/10.1186/1743-7075-1-2.

29. Paoli A, Cenci L, Grimaldi KA. Effect of ketogenic Mediterranean diet with phytoextracts and low carbohydrates/high-protein meals on weight, cardiovascular risk factors, body composition and diet compliance in Italian council employees. Nutr J. 2011;10(1):112. https://doi.org/10.1186/1475-2 891-10-112.

30. Paoli A, Moro T, Bosco G, Bianco A, Grimaldi KA, Camporesi E, et al. Effects of n-3 polyunsaturated fatty acids (omega-3) supplementation on some cardiovascular risk factors with a ketogenic Mediterranean diet. Mar Drugs. 2015:13(2):996-1009. https://doi.org/10.3390/md13020996.

31. CJ DCH, Schofield GM, Williden M, JA MQ. The effect of medium chain triglycerides on time to nutritional ketosis and symptoms of keto-induction in healthy adults: a randomised controlled clinical trial. J Nutr Metab. 2018; 2018:2630565.

32. Jager R, Kerksick CM, Campbell BI, Cribb PJ, Wells SD, Skwiat TM, et al. International Society of Sports Nutrition Position Stand: protein and exercise. J Int Soc Sports Nutr. 2017;14(1):20. https://doi.org/10.1186/s12970017-0177-8

33. Black KE, Skidmore PM, Brown RC. Energy intakes of ultraendurance cyclists during competition, an observational study. Int J Sport Nutr Exerc Metab. 2012;22(1):19-23. https://doi.org/10.1123/ijsnem.22.1.19.

34. Control CfD, Prevention: NHANES Anthropometry Procedures Manual. http://www.cdc.gov/nchs/data/nhanes/bm.pdf. Accessed 2015

35. Weir JB. New methods for calculating metabolic rate with special reference to protein metabolism. J Physiol. 1949;109(1-2):1-9. https://doi.org/10.1113/ jphysiol.1949.sp004363.

36. Rubini A, Bosco G, Lodi A, Cenci L, Parmagnani A, Grimaldi K, et al. Erratum to: effects of twenty days of the ketogenic diet on metabolic and respiratory parameters in healthy subjects. Lung. 2017;195(1):155. https://doi. org/10.1007/s00408-016-9958-0.

37. Chaouachi A, Leiper JB, Chtourou H, Aziz AR, Chamari K. The effects of Ramadan intermittent fasting on athletic performance: recommendations for the maintenance of physical fitness. J Sports Sci. 2012;30(Suppl 1):S5373. https://doi.org/10.1080/02640414.2012.698297.

38. Deprez D, Fransen J, Lenoir M, Philippaerts R, Vaeyens R. The Yo-Yo intermittent recovery test level 1 is reliable in young high-level soccer players. Biol Sport. 2015;32(1):65-70. https://doi.org/10.5604/20831862.1127284.

39. Slinde F, Suber C, Suber L, Edwen CE, Svantesson U. Test-retest reliability of three different countermovement jumping tests. J Strength Cond Res. 2008; 22(2):640-4. https://doi.org/10.1519/JSC.0b013e3181660475.

40. Wang Z, Deurenberg P, Wang W, Pietrobelli A, Baumgartner RN, Heymsfield SB. Hydration of fat-free body mass: review and critique of a classic bodycomposition constant. Am J Clin Nutr. 1999;69(5):833-41. https://doi.org/1 0.1093/ajcn/69.5.833.

41. Burke LM, Whitfield J, Heikura IA, Ross MLR, Tee N, Forbes SF, et al. Adaptation to a low carbohydrate high fat diet is rapid but impairs endurance exercise metabolism and performance despite enhanced glycogen availability. J Physiol. 2021;599(3):771-90. https://doi.org/10.1113/ JP280221.

42. Shaw DM, Merien F, Braakhuis A, Keaney L, DulsonDK. Adaptation to a ketogenic diet modulates adaptive and mucosal immunemarkers in trained male endurance athletes. Scand JMed Sci Sports. 2021;31(1):140-52. https:// doi.org/10.1111/sms.13833.

43. Burke LM, Sharma AP, Heikura IA, Forbes SF, Holloway M, McKay AKA, et al. Crisis of confidence averted: impairment of exercise economy and performance in elite race walkers by ketogenic low carbohydrate, high fat (LCHF) diet is reproducible. PLoS One. 2020;15(6):e0234027. https://doi.org/1 0.1371/journal.pone.0234027

44. Sjodin A, Hellstrom F, Sehlstedt E, Svensson M, Buren J. Effects of a Ketogenic Diet on Muscle Fatigue in Healthy, Young, Normal-Weight Women: A Randomized Controlled Feeding Trial. Nutrients. 2020;12(4):955 https://doi.org/10.3390/nu12040955. 
45. Burke LM. Ketogenic low-CHO, high-fat diet: the future of elite endurance sport? J Physiol. 2021;599(3):819-43. https://doi.org/10.1113/JP278928.

46. Maughan RJ, Burke LM, Dvorak J, Larson-Meyer DE, Peeling P, Phillips SM, et al. IOC consensus statement: dietary supplements and the highperformance athlete. Br J Sports Med. 2018;52(7):439-55. https://doi.org/1 0.1136/bjsports-2018-099027.

47. Youm YH, Nguyen KY, Grant RW, Goldberg EL, Bodogai M, Kim D, et al. The ketone metabolite beta-hydroxybutyrate blocks NLRP3 inflammasomemediated inflammatory disease. Nat Med. 2015;21(3):263-9. https://doi.org/1 $0.1038 / \mathrm{nm} .3804$

48. Thomsen HH, Rittig N, Johannsen M, Moller AB, Jorgensen JO, Jessen N, et al. Effects of 3-hydroxybutyrate and free fatty acids on muscle protein kinetics and signaling during LPS-induced inflammation in humans: anticatabolic impact of ketone bodies. Am J Clin Nutr. 2018;108(4):857-67. https://doi.org/10.1093/ajcn/nqy170.

49. Reidy PT, Rasmussen BB. Role of ingested amino acids and protein in the promotion of resistance exercise-induced muscle protein anabolism. J Nutr. 2016;146(2):155-83. https://doi.org/10.3945/jn.114.203208.

50. Paoli A, Cancellara P, Pompei P, Moro T. Ketogenic diet and skeletal muscle hypertrophy: a frenemy relationship? J Hum Kinet. 2019;68(1):233-47. https://doi.org/10.2478/hukin-2019-0071.

51. Koutnik AP, D'Agostino DP, Egan B. Anticatabolic effects of ketone bodies in skeletal muscle. Trends Endocrinol Metab. 2019;30(4):227-9. https://doi.org/1 0.1016/j.tem.2019.01.006

52. Sawyer JC, Wood RJ, Davidson PW, Collins SM, Matthews TD, Gregory SM, et al. Effects of a short-term carbohydrate-restricted diet on strength and power performance. J Strength Cond Res. 2013;27(8):2255-62. https://doi. org/10.1519/JSC.0b013e31827da314.

53. Wilson JM, Lowery RP, Roberts MD, Sharp MH, Joy JM,Shields KA, et al. The effects of ketogenic dieting on body composition,Strength, Power, and Hormonal Profiles in Resistance Training Males. I StrengthCond Res. 2020; 34(12):3463-74. https://doi.org/10.1519/JSC.0000000000001935.

54. Vargas-Molina S, Petro JL, Romance R, Kreider RB, Schoenfeld BJ, Bonilla DA, et al. Effects of a ketogenic diet on body composition and strength in trained women. J Int Soc Sports Nutr. 2020;17(1):19. https://doi.org/10.1186/ s12970-020-00348-7.

55. Burke LM. Re-examining high-fat diets for sports performance: did we call the 'Nail in the Coffin' too soon? Sports Med. 2015;45(Suppl 1):S33-49

56. Zinn C, Wood M, Williden M, Chatterton S, Maunder E. Ketogenic diet benefits body composition and well-being but not performance in a pilot case study of New Zealand endurance athletes. J Int Soc Sports Nutr. 2017; 14(1):22. https://doi.org/10.1186/s12970-017-0180-0.

57. Wroble KA, Trott MN, Schweitzer GG, Rahman RS, Kelly PV, Weiss EP. Lowcarbohydrate, ketogenic diet impairs anaerobic exercise performance in exercise-trained women and men: a randomized-sequence crossover trial. J Sports Med Phys Fitness. 2019;59(4):600-7. https://doi.org/10.23736/50022-4 707.18.08318-4.

58. Garthe I, Raastad T, Refsnes PE, Koivisto A, Sundgot-Borgen J. Effect of two different weight-loss rates on body composition and strength and powerrelated performance in elite athletes. Int J Sport Nutr Exerc Metab. 2011; 21(2):97-104. https://doi.org/10.1123/ijsnem.21.2.97.

59. Bueno NB, de Melo IS, de Oliveira SL, da Rocha AT. Very-low-carbohydrate ketogenic diet $\mathrm{v}$. low-fat diet for long-term weight loss: a meta-analysis of randomised controlled trials. Br J Nutr. 2013;110(7):1178-87. https://doi.org/1 $0.1017 / 50007114513000548$.

60. Paoli A. Ketogenic diet for obesity: friend or foe? Int J Environ Res Public Health. 2014;11(2):2092-107. https://doi.org/10.3390/ijerph110202092.

61. Hall KD, Bemis T, Brychta R, Chen KY, Courville A, Crayner EJ, et al. Calorie for calorie, dietary fat restriction results in more body fat loss than carbohydrate restriction in people with obesity. Cell Metab. 2015;22(3):427-36. https://doi.org/10.1016/j.cmet.2015.07.021.

62. Ebbeling CB, Swain JF, Feldman HA, Wong WW, Hachey DL, Garcia-Lago E, et al. Effects of dietary composition on energy expenditure during weightloss maintenance. JAMA. 2012;307(24):2627-34. https://doi.org/10.1001/ja ma.2012.6607.

63. Ludwig DS, Dickinson SL, Henschel B, Ebbeling CB, Allison DB. Do lowercarbohydrate diets increase Total energy expenditure? An updated and reanalyzed Meta-analysis of 29 controlled-feeding studies. 2021;151 (3):482-90. https:/doi.org/10.1093/jn/nxaa350.
64. Ravussin E, Bogardus C. Relationship of genetics, age, and physical fitness to daily energy expenditure and fuel utilization. Am J Clin Nutr. 1989;49(5 Suppl):968-75. https://doi.org/10.1093/ajcn/49.5.968.

65. Tagliabue A, Bertoli S, Trentani C, Borrelli P, Veggiotti P. Effects of the ketogenic diet on nutritional status, resting energy expenditure, and substrate oxidation in patients with medically refractory epilepsy: a 6-month prospective observational study. Clin Nutr (Edinburgh, Scotland). 2012;31 (2):246-9.

66. Ebbeling CB, Feldman HA, Klein GL, Wong JMW, Bielak L, Steltz SK, et al. Effects of a low carbohydrate diet on energy expenditure during weight loss maintenance: randomized trial. BMJ. 2018;363:k4583.

67. Hall KD, Chen KY, Guo J, Leibel RL, Mayer LE, Reitman ML, et al. Reply to DS Ludwig and CB Ebbeling. Am J Clin Nutr. 2016;104(5):1488-90. https://doi. org/10.3945/ajcn.116.143628.

68. Cunha GM, Correa de Mello LL, Hasenstab KA, spina L, Bussade I, Prata Mesiano JM, et al. MRI estimated changes in visceral adipose tissue and liver fat fraction in patients with obesity during a very low-calorie-ketogenic diet compared to a standard low-calorie diet. Clin Radiol. 2020.

69. Moreno B, Crujeiras AB, Bellido D, Sajoux I, Casanueva FF. Obesity treatment by very low-calorie-ketogenic diet at two years: reduction in visceral fat and on the burden of disease. Endocrine. 2016;54(3):681-90. https://doi.org/10.1 007/s12020-016-1050-2.

70. Valenzano A, Polito R, Trimigno V, Di Palma A, Moscatelli F, Corso G, et al. Effects of Very Low Calorie Ketogenic Diet on the Orexinergic System, Visceral Adipose Tissue, and ROS Production. Antioxidants (Basel). 2019; 8(12):643. https://doi.org/10.3390/antiox8120643.

71. Castro Al, Gomez-Arbelaez D, Crujeiras AB, Granero R, Aguera Z, JimenezMurcia S, et al. Effect of A Very Low-Calorie Ketogenic Diet on Food and Alcohol Cravings, Physical and Sexual Activity, Sleep Disturbances, and Quality of Life in Obese Patients. Nutrients. 2018;10(10):1348. https://doi. org/10.3390/nu10101348.

72. Perissiou M, Borkoles E, Kobayashi K, Polman R. The Effect of an 8 Week Prescribed Exercise and Low-Carbohydrate Diet on Cardiorespiratory Fitness, Body Composition and Cardiometabolic Risk Factors in Obese Individuals: A Randomised Controlled Trial. Nutrients. 2020;12(2):492. https://doi.org/10.33 90/nu12020482

73. Cohen CW, Fontaine KR, Arend RC, Alvarez RD, Leath CA III, Huh WK, et al. A ketogenic diet reduces central obesity and serum insulin in women with ovarian or endometrial Cancer. J Nutr. 2018;148(8):1253-60. https://doi.org/1 $0.1093 / \mathrm{jn} / \mathrm{nxy} 119$

74. Wensveen FM, Valentic S, Sestan M, Turk Wensveen T, Polic B. The "big bang" in obese fat: events initiating obesity-induced adipose tissue inflammation. Eur J Immunol. 2015;45(9):2446-56. https://doi.org/10.1002/ eji.201545502.

75. Del Buono A, Battery L, Denaro V, Maccauro G, Maffulli N. Tendinopathy and inflammation: some truths. Int J Immunopathol Pharmacol. 2011;24(1 Suppl 2):45-50. https://doi.org/10.1177/03946320110241S209.

76. Duren DL, Sherwood RJ, Czerwinski SA, Lee M, Choh AC, Siervogel RM, et al. Body composition methods: comparisons and interpretation. J Diabetes Sci Technol. 2008;2(6):1139-46. https://doi.org/10.1177/193229680800200623.

\section{Publisher's Note}

Springer Nature remains neutral with regard to jurisdictional claims in published maps and institutional affiliations.

Ready to submit your research? Choose BMC and benefit from:

- fast, convenient online submission

- thorough peer review by experienced researchers in your field

- rapid publication on acceptance

- support for research data, including large and complex data types

- gold Open Access which fosters wider collaboration and increased citations

- maximum visibility for your research: over $100 \mathrm{M}$ website views per year

At BMC, research is always in progress.

Learn more biomedcentral.com/submissions 